\title{
FALSAFAH AJARAN KYAI AHMAD DAHLAN DAN ETOS PENDIDIKAN MUHAMMADIYAH
}

\author{
Ahmad Ruslan ${ }^{1}$
}

\begin{abstract}
Looking at the history of Islamic education in Indonesia, it can be seen that its development has started since the entry of Islam to Indonesia, which is estimated to be in the 12th century $A D$. Muhammadiyah was present as a pioneer, had a big role as the foundation for integration between religious style pesantren education and general education, which at that time was dominated by the Dutch. This cannot be separated from the philosophy of Kyai Ahmad Dahlan's teachings. With this background, this study aims to analyze the philosophy of Kyai Ahmad Dahlan's teachings and the ethos of Muhammadiyah education for Indonesian education. This research uses qualitative methods with data collection techniques using documentation study instruments. The results found that there are practices in the world of Muhammadiyah Education that reflect the seven philosophies of Kyai Dahlan's teachings, namely: (1) based on the purpose of life; (2) not being arrogant; (3) not taqlid; (4) optimizing reason; (5) being brave for the truth; (6) making sacrifices for many people; and (7) a combination of knowledge / theory with practice ('Ilmu amaliyah). These seven philosophies become important as a reference for the role model of Muhammadiyah education, which is not only worldly oriented but also has a long term afterlife, and always adheres to the values of courage. As a reference, education in Indonesia must also be oriented towards how to create human beings who are "progressive Kyai" or people who are intellectual-ulama.
\end{abstract}

Keywords: Teaching Philosophy, Kyai Ahmad Dahlan, Indonesian Education.

\begin{abstract}
Abstrak
Melihat sejarah pendidikan Islam di Indonesia terlihat bahwa perkembangannya telah dimulai sejak masuknya Islam ke Indonesia yang diperkirakan pada abad ke 12 Masehi. Muhammadiyah hadir sebagai pelopor, mempunyai andil besar sebagai peletak dasar integrasi antara pendidikan pesantren yang bercorak keagamaan dengan pendidikan umum, yang pada masanya didominasi oleh orang Belanda. Hal tersebut tidak terlepas dari falsafah ajaran Kyai Ahmad Dahlan. Dengan latar belakang tersebut, penelitian ini bertujuan untuk menganalisis falsafah ajaran Kyai Ahmad Dahlan dan etos pendidikan Muhammadiyah untuk pendidikan Indonesia. Penelitian ini menggunakan metode kualitatif dengan teknik pengumpulan datanya menggunakan instrumen kajian dokumen. Hasilnya ditemukan bahwa terdapat praktik-praktik dalam dunia pendidikan Indonesia yang mencerminkan tujuh falsafah ajaran Kyai Dahlan, yaitu: (1) berlandaskan pada tujuan hidup; (2) tidak sombong; (3) tidak taqlid; (4) mengoptimalkan akal; (5) berani untuk kebenaran; (6) berkorban untuk orang banyak; dan (7) adanya kombinasi pengehuan/teori dengan praktik (ilmu amaliyah). Ketujuh falsafah tersebut, menjadi penting sebagai acuan role model pendidikan di Indonesia yang bukan hanya berorientasi keduniawian, namun juga ada jangka panjang akhirat, dan selalu berpegang teguh pada nilai-nilai kebenaran. Dengan demikian, pendidikan di Indonesia harus diorientasikan pada proses menciptakan manusia yang "Kyai yang berkemajuan" atau orang yang intelekulama atau ulama yang intelek.
\end{abstract}

Kata Kunci : Falsafah Ajaran, Kyai Ahmad Dahlan, Pendidikan Indonesia.

\footnotetext{
${ }^{1}$ Universitas Negeri Jakarta, ahmadruslan063@gmail.com
} 


\section{PENDAHULUAN}

Sejak dahulu hingga sekarang pondok pesantren tidak lagi asing terdengar di telinga kita. Pesantren dahulunya dipimpin oleh seorang Kyai, dan para ustadz sebagai tenaga pengajarnya, dengan jumlah murid tidak menentu tergantung dari pondok pesantren itu sendiri, apakah pondok pesantren yang terkenal atau tidak. Untuk melihat seberapa besar minatnya dari pondok pesantren tersebut adalah dilihat dari banyaknya jumlah murid yang belajar di pondok tersebut. Dengan kata lain, di Indonesia sendiri pesantren dapat dikatakan sebagai pelopor pendidikan Islam pertama di Nusantara.

Yunus (1960) menyatakan bahwa eksistensi kurikulum pendidikan Islam yang ada di Indonesia tidak terlepas dari sejarah yang menaunginya. Setiap periode dari kurikulum tersebut selalu berubah-ubah sesuai dengan perubahan zaman. Semakin besar pengaruh zaman tersebut, maka semakin besar pula tugas lembaga pendidikan dalam mengajarkan kepada anak didiknya. Jika dilihat dari sejarah, bahwa perkembangan dari pendidikan Islam telah dimulai sejak masuknya Islam ke Indonesia yang diperkirakan pada abad ke 12 Masehi (Aslan, 2018).

Muhammadiyah hadir sebagai pelopor, dalam perkembangannya banyak sekali hal-hal baru Muhammadiyah lakukan, baik dalam konteks keagamaan, kesehatan, pendidikan, dan sosial-budaya. Hal itulah yang kemudian Muhammadiyah dinobatkan sebagai salah satu pelopor kebangkitan nasional, seperti halnya Budi Utomo, Sarekat Islam, dan lain-lain.

Terkhusus masalah Pendidikan, Muhammadiyah mempunyai andil besar sebagai peletak dasar integrasi antara pendidikan pesantren yang bercorak keagamaan dengan pendidikan umum, yang pada masanya didominasi oleh orang Belanda. Meskipun di awal inisiasi gerakan Kyai Dahlan tersebut banyak ditolak, bahkan dimusuhi oleh sebagian masyarakat, khususnya di Kauman, Yogyakarta.

Perjuangan tersebut akhirnya membuahkan hasil, perlahan tapi pasti muridmurid Kyai Dahlan semakin banyak, bahkan dalam perkembangannya, murid-murid perempuan juga ikut serta. Dalam jangka panjang, perkembangan pendidikan pada masanya pun semakin maju. Hal tersebut tidak terlepas dari falsafah ajaran Kyai Dahlan yang juga tidak terlepas dari filsafat pendidikan Kiai Ahmad Dahlan yang menjadi latar belakang dalam filsafat pendidikan Muhammadiyah secara umum, yakni perilaku altruis dan eklektik (Andi, Riadi, \& Absor, 2020). Dengan latar belakang tersebut, penelitian ini bertujuan untuk menganalisis falsafah ajaran Kyai Ahmad Dahlan dan etos pendidikan Muhammadiyah untuk pendidikan Indonesia. 


\section{METODE}

Peneliti dalam memberikan jawaban sesuai dengan fokus penelitian melalui metode kualitatif dengan kajian dokumen. Kajian dokumen dianggap sebagai analisis dokumen, yang terdiri buku, artikel, internet dan bahan-bahan yang sesuai dengan penelitian. Adapun cara-cara dalam pengumpulan datanya, pertama, melalui kajian kepustakaan yang sesuai dengan bahan yang akan diteliti. Kedua, setelah data-data telah diperoleh oleh peneliti, maka selanjutnya menganalisis datanya melalui metode deskriptif sesuai dengan pemahaman peneliti dalam melakukan kajian ini (Muhammad Hasan, 2016). Sementara itu, untuk teknik analisis data sendiri menggunakan model Miles dan Huberman yang tahapan-tahapannya adalah sebagai berikut: (1) Reduksi data; (2) Penyajian data; (3) Kesimpulan atau verifikasi (Sugiyono, 2015).

\section{HASIL DAN PEMBAHASAN}

K.H. Ahmad Dahlan mendirikan Muhammadiyah pada tanggal 18 Zulhijjah $1330 \mathrm{H}$, atau bertepatan dengan tanggal 18 Desember 1912. Ahmad Dahlan bernama kecil Muhammad Darwisy lahir pada tahun 1868 di Kampung Kauman Yogyakarta dan meninggal dunia pada tanggal 25 Febuari 1923 dalam usia 55 tahun. Ayahnya K.H. Abubakar bin K.H. Muhammad Sulaiman adalah pejabat Kepengulon Kesultanan Yogyakarta Hadiningrat dengan gelar Penghulu Katib di Mejid Besar Kesultanan. Sedang ibunya, Nyai Abubakar, adalah putri K.H. Ibrohim bin K.H. Hasan yang juga pejabat Kepengulongan Yogyakarta (M. Yunan Yusuf, 2005).

Menurut Abdullah (2000), Muhammadiyah sejak awal didirikan, telah memerankan diri sebagai Lembaga Swadaya Masyarakat (LSM) atau Non Governmental Organization (NGO) yang terus terlibat aktif dalam pengembangan dan pemberdayaan masyarakat di bidang sosial, budaya, pendidikan, pelayanan kesehatan, ekonomi, dan lain-lain secara mandiri sambil bekerja sama dengan pemerintah.

Menurut Khoiruddin (2017), terdapat tiga garapan utama sebagai ranah aktivitas dakwah Muhammadiyah dan telah menjadi semacam brand organisasi ini. Pertama, schooling, yang bermakna bidang pendidikan dengan cara mendirikan sekolah-sekolah modern. Kedua, healing, yakni bidang pelayanan sosial dengan mendirkan balai pengobatan, poliklinik dan rumah sakit. Ketga, feeding, yang artinya bergerak di bidang sosial menyantuni anak yatim dan fakir miskin dengan cara mendirikan panti asuhan anak yatim dan panti jompo (Suwarno, 2019). 
Salah satu karakter Muhammadiyah yang paling menonjol sejak awal kelahiran, pertumbuhan dan perkembangannya, adalah posisi organisasi ini sebagai gerakan tajdid. Tajdid di sini bermakna pemurnian (purification) sekaligus pembaruan (reformation). Pemurnian mengandung arti Muhammadiyah ingin memurnikan pengamalan keberagamaan (aspek ibadah) ummat Islam yang telah bercampur baur dengan takhayul, bid'ah dan khurafat (TBKh). Sementara pembaruan berarti Muhammadiyah ingin umat Islam dapat menyesuaikan diri dengan kehidupan modern (aspek muamalah). Dengan posisi sebagai gerakan tajdid, artinya, sejak awal didirikan Muhammadiyah merupakan bagian dan sekaligus mata rantai dari gerakan pembaruan Islam modern, terutama yang berkiblat pada gagasan tokoh pembaru Islam dari Mesir, Syeikh Muhammad Abduh (1849 - 1905) (H.A.R. \& Gibb, 1993). Hal tersebut tidak terlepas dari Sang Pelopor, Ahmad Dahlan.

Dalam pandangan Maarif (2000), Ahmad Dahlan selaku pendiri Muhammadiyah dikenal sebagai salah seorang ulama yang sangat peka dan bahkan mungkin yang paling gelisah pada zamannya karena menyadari sepenuhnya bahwa kondisi umat Islam Indonesia ketika itu sedang terpuruk tanpa harkat dan martabat. Fenomena yang merupakan realitas sosial umat Islam pada saat itu adalah kemiskinan, keterbelakangan dan kebodohan dalam beragama. Tantangan tersebut dijawab oleh Ahmad Dahlan dengan perbuatan konkret, yakni umat harus dicerdaskan dan dicerahkan. Artinya, penyakit-penyakit sosial tidak dapat diobati tanpa aksi nyata. Tidak heran bila Ahmad Dahlan merupakan sosok man of action yang sangat tanggap terhadap tantangan zamannya. Filosofi sosial yang diajarkan oleh Ahmad Dahlan, yaitu berbuat dan beramal sebagai perintah iman, selanjutnya berkembang menjadi trade mark-nya Muhammadiyah hingga sekarang. Muhammadiyah tidak akan pernah melupakan misi sosial, pendidikan, dan kemanusiaan yang telah melekat menjadi jati diri gerakan Muhammadiyah.

Seperi yang telah disebarluaskan oleh murid beliau, Hadjid, yang menurut peneliti masih relevan dengan kondisi umat Islam sekarang. Ketujuh falsafah ajaran Ahmad Dahlan adalah:

1. "Kita, manusia ini, hidup di dunia hanya sekali, untuk bertaruh: sesudah mati, akan mendapat kebahagiaankah atau kesengsaraankah?"

2. "Kebanyakan manusia berwatak angkuh dan takabbur, mereka mengambil keputusan sendiri-sendiri."

3. "Manusia itu kalau mengerjakan pekerjaan apapun berulang-ulang hingga menjadi biasa. Kalau sudah menjadi kebiasaan yang disenangi 
maka sulit sekali untuk diubah (menjadi semacam i'tiqad / keyakinan, dan taqlid pada keyakinan itu)."

4. "Manusia harus mempergunakan akal pikirannya untuk memahami agama dan mencari kebenaran yang sejati."

5. "Kebanyakan manusia hidup asal hidup, hidup sebagai makhluk yang tak berakal, dan tidak menetapi kebenaran."

6. "Kebanyakan pemimpin tidak mau berkorban, malahan suka memperalat dan mempermainkan manusia yang lemah dan bodoh."

7. "Belajar, khususnya belajar agama, harus mempelajari teori dan mempraktikkannya, agar ilmu yang dimilikinya bermanfaat." (K.R.H. Hajid, 2005).

Ahmad Dahlan, menurut kesaksian Syuja', merupakan seorang alim yang sudah merasa dan mengaku bahwa dirinya telah menempati posisi dan kursi ulama yang harus mempunyai tanggung jawab besar atas masyarakatnya di mata Tuhan, menyadari betul akan baik dan buruk, serta sesat dan benarnya pengamalan agama umat Islam. Dengan kesadaran yang menyejarah itulah, Ahmad Dahlan terpanggil untuk menyelamatkan umat Islam dari kesesatan, mengentaskan umat Islam dari kondisi kemiskinan, kebodohan dan ketrebelakangan, serta memberikan pencerahan dengan cara mendirikan persyarikatan Muhammadiyah. Arah yang dituju oleh Ahmad Dahlan adalah umat Islam di masa depan yang lebih baik, beriman, cerdas, menguasai ilmu pengetahuan, teknologi dan seni (Ipteks), berakhlak mulia, serta tentu saja lebih beradab dan berjaya (K.H. Syuja', 2009).

Beberapa argumen tersebut yang kemudian menjadi penguat gerakan Muhammadiyah dalam lintas gerakan, baik gerakan keagamaan, kesehatan, pendidikan, dan sosial. Dengan harapan umat Islam ke depan tidak tertinggal, terjajah, serta terbelenggu oleh kebodohan dan kemiskinan. Kedua hal tersebut yang menjadi alasan utama selama ini mengapa umat Islam terkesan tertinggal.

Tekhusus dunia Pendidikan dalam pandangan KH Ahmad Dahlan, tujuan pendidikan: dadiyo kyai sing ke-majuan, lan aja kesel-kesel anggonmu nyambut gawe kanggo Muhammadiyah, (Wirjosukarto, 1962) terjemahan dalam bahasa Indonesia kurang lebih: jadilah ulama yang berkemajuan, dan tidak kenal lelah bekerja/beramal bagi Muhammadiyah. Kata-kata Kyai Dahlan tersebut dapat diinterpretasikan bahwa tujuan pendidikan Muhammadiyah menurutnya adalah untuk mewujudkan dan menumbuhkan manusia religius, orang Islam yang menguasai "ilmu-ilmu agama" maupun "ilmu-ilmu umum" sekaligus di mana secara 
individual seluruh potensi/fitrahnya tumbuh optimal sehingga bisa menjadi pribadi yang cerdas (inteligence), yaitu pribadi yang bersedia berjuang atau bekerja untuk memecahkan masalah-masalah sosial-kemasyarakatan dan menggerakkan ke arah kemajuan (progress). Dengan demikian, secara singkat kyai berkemajuan adalah ulama yang bersedia terlibat dan mampu memecahkan permasalahan sosialkehidupan yang dihadapi masyarakat. Karena kebenaran agama maupun ilmu dalam pandangan kyai Dahlan harus diuji secara "pragmatis", yaitu kegunaan secara fungsional untuk memecahkan problematika kehidupan yang muncul silih berganti (Ali, 2016).

Selanjutnya Ali (2016), menambahkan bahwa tujuan pendidikan Muhammadiyah lebih dekat dengan teori pendidikan progresif. Ini dapat ditunjukkan dari konsep-konsep berikut: "kyai sing berkemajuan”, “aja kesel-kesel anggomu nyambut gawe kanggo Muhammadiyah", "memajukan dan menggembirakan cara kehidupan", "berguna bagi masyarakat", dan Iain-lain. Meskipun tujuan pendidikan Muhammadiyah berorientasi dan lebih dekat dengan teori pendidikan progresif, namun harus dicatat bahwa fondasi pendidikan Muhammadiyah adalah religius, yaitu Islam yang berkemajuan. Sedangkan progresivisme bercorak sekular. Oleh karena itu, secara ringkas dapat disimpulkan bahwa tujuan pendidikan Muhammadiyah bercorak progresif religious.

Muhammadiyah merupakan konsekuensi logis munculnya pertanyaan sederhana seorang muslim kepada diri dan masyarakatnya tentang bagaimana memahami dan mengamalkan kebenaran Islam agar hal-hal yang telah dialami sebagai pesan global Islam "Rahmatan lil Alamin" atau kesejahteraan bagi seluruh alam dapat diwujudkan dalam kehidupan obyektif umat manusia. Dari hal tersebut, maka kelahiran Muhammadiyah merupakan bagian dari daya kreatif umat Islam Indonesia. Oleh karena itu, maka sejarah perkembangan Muhammadiyah adalah bagian dinamika dan dinamisme daya kreatif intelek manusia muslim dari berbagai persoalan hidupnya dengan norma ajaran Islam (Mulkhan, 1990).

Muhammadiyah sebagai organisasi yang bergerak di bidang pendidikan, dakwah dan kemasyarakatan dengan pola dasar perjuangannya dakwah, amal ma'ruf nahi mungkar sebagai salah satu pemahaman firman Allah dalam Q.S. Ali Imran ayat 104. Muhammadiyah se-Indonesia mengembangkan amal dan usaha tidak terkecuali di Kota Sorong. Setiap anggota Muhammadiyah punya kewajiban prihatin dengan lingkungannya, terutama di bidang pendidikan. Hal inilah yang dapat dilihat di Kota Sorong, Muhammadiyah membangun lembaga pendidikan dari hasil 
solidaritas para anggotanya. Pendidikan Islam adalah pendidikan yang berdasarkan ajaran Islam atau tuntutan agama Islam dalam usaha membina dan membentuk pridabi muslim yang bertakwa kepada Allah Swt. Pendidikan Islam merupakan salah satu disiplin ilmu ke-Islam-an yang membahas objek-objek di seputar kependidikan. Pemahaman hakikat pendidikan Islam sebenarnya tercermin di dalam sejarah dan falsafah Islam sendiri, sebab setiap proses pendidikan tidak terlepas dari objek-objek ke-Islam-an. Pendidikan Islam adalah proses mengubah tingkah laku individu pada kehidupan pribadi, masyarakat, dan sekitarnya, dengan cara pengajaran sebagai suatu aktivitas asasi dan sebagai prosesi di antara profesi-prosesi asasi dalam masyarakat (Umar, 2010).

Menurut KH. Ahmad Dahlan lembaga pendidikan Islam harus dikelola sebaik mungkin, $\mathrm{KH}$. Ahmad Dahlan lantas membuka sekolah sendiri yang diatur dengan rapi dan didukung oleh organisasi yang bersifat permanen. Hal tersebut dimaksudkan untuk menghindari nasib seperti pesantren tradisional yang terpaksa tutup bila Kyai sebagai pemimpinnya meninggal dunia (Ni'mah, 2014). Artinya dalam hal ini Ahmad Dahlan memiliki pikiran yang visioner ke depan, memikirkan suatu cara sebaiknya sebuah lembaga pendidikan dirawat dengan baik, selain itu juga berkelanjutan jangka panjang. Meskipun founder/kyai/gurunya sudah tiada, akan tetap berlangsung oleh generasi-generasi selanjutnya. Terbukti sampai sekarang, banyaknya lembaga Pendidikan yang mampu bertahan, tidak lain karena ide genuine Ahmad Dahlan dalam mengintegrasikan pendidikan pesantren dan pendidikan formal pada masanya.

\section{KESIMPULAN}

Muhammadiyah lahir, bukan hanya untuk kepentingan Ahmad Dahlan sendiri atau keluarganya semata. Bahkan inisiasi dibentuknya sebuah organisasi pun berangkat dari usulan muridnya sendiri. Artinya memang orientasi dibentuknya Muhammadiyah jauh dari proyeksi kepentingan personal. Muhammadiyah sendiri bergerak dalam bidang keagamaan, kesehatan, pendidikan, dan sosial kemasyarakatan. Dengan kata lain, ada misi keumatan sekaligus misi kebangsaan yang mendasari dibentuknya Muhammadiyah.

Berangkat dari kegelisahan yang dirasakan oleh Ahmad Dahlan, Muhammadiyah hadir sebagai solusi zaman. Memberikan cahaya terang pada gelapnya kebodohan dan kemiskinan umat Islam pada masa itu, khususnya di 
Kauman yang masih terjebak dalam Takhayul, Bid'ah, dan Churafat. Hal tersebut yang membelenggu kejernihan nilai-nilai praktik keislaman bertahun-tahun lamanya.

Ahmad Dahlan hadir sebagai penggagas, pelopor, sekaligus aktor gerakan pencerahan Muhammadiyah. Ahmad Dahlan dalam prinsip dan metode dakwahnya selalu mencoba mengedepankan perihal kecontohan (uswah), tidak hanya berhenti di teori. Artinya ada nilai-nilai yang Ahmad Dahlan berikan kepada murid-muridnya melalui praktik. Kemudian Ahmad Dahlan juga mengenalkan tujuh ajarannya, yang menjadi pegangan berharga bagi murid-muridnya sebagai pionir-pionir gerakan dakwah Islam berkemajuan, yakni (1) berlandaskan pada tujuan hidup; (2) tidak sombong; (3) tidak taqlid; (4) mengoptimalkan akal; (5) berani untuk kebenaran; (6) berkorban untuk orang banyak; dan (7) adanya kombinasi pengehuan/teori dengan praktik (ilmu amaliyah). Misi mulia Ahmad Dahlan yang kemudian tertuang dalam setiap gagasan Muhammadiyah dalam dunia pendidikan adalah proses menjadikan manusia yang "intelek-ulama" dan "ulama yang intelek". Terlihat jelas bahwa adanya integrasi yang coba Muhammadiyah wujudkan, yaitu agar umat Islam ini maju tanpa meninggalkan jati diri ke-Islam-annya. Seimbang dunia dan akhirat.

\section{DAFTAR PUSTAKA}

Abdullah, M. A. (2000). Muhammadiyah's Experience in Promoting A Civil Society dalam Profetika. Jurnal Studi Islam, 2(1).

Ali, M. (2016). Membedah Tujuan Pendidikan Muhammadiyah. Profetika: Jurnal Studi Islam, 17(01), 43-56. https://doi.org/10.23917/profetika.v17i01.2099

Andi, A., Riadi, S., \& Absor, N. F. (2020). Perilaku Altruistik dan Eklektik dalam Praksis Pendidikan Kiai Ahmad Dahlan. JURNAL YAQZHAN: Analisis Filsafat, Agama Dan Kemanusiaan, 6(1), 1-15.

Aslan, A. (2018). Dinamika Pendidikan Islam di Zaman Penjajahan Belanda. SYAMIL: Jurnal Pendidikan Agama Islam (Journal of Islamic Education), Volume 6 (, 39-50. https://doi.org/10.21093/sy.v6i1.1024

H.A.R., \& Gibb. (1993). Aliran-aliran Moderen dalam Islam, terjemahan Machnun Husein. Jakarta: Citra Niaga Rajawali Pers.

K.H. Syuja'. (2009). Islam Berkemajuan Kisah Perjuangan K.H. Ahmad Dahlan dan Muhammadiyah Masa Awal. Yogyakarta: Al-Wasat.

K.R.H. Hajid. (2005). Pelajaran K.H. A. Dahlan 7 Falsafah Ajaran dan 17 Kelompok Ayat Al-Quran. Malang: UMM Press.

Khoiruddin., Z. B. dan A. (2017). Etika Muhammadiyah dan Spirit Peradaban. Yogyakarta: Suara Muhammadiyah.

M. Yunan Yusuf, E. al. (2005). Ensiklopedi Muhammadiyah. Yogyakarta: Raja Grafindo Persada dan Dikdasmen PP. Muhammadiyah.

Maarif, A. S. (2000). "Revitalisasi Ideologi Gerakan Muhammadiyah," Rekonstruksi 
Gerakan Muhammadiyah pada Era Multiperadaban (D. Edy \& M. D. H. dan S. S. (penyunting) Suandi Hamid, eds.). Yogyakarta: UII Press.

Muhammad Hasan, D. (2016). Peranan Ulama Banjar Abad Ke-20 dalam Tradisi Penulisan Hadis Arba'in di Banjar dan Malaysia. Al-Banjari; Jurnal IImiah IImuIImu Keislaman, 15(2), 4.

Mulkhan, A. M. (1990). Pemikiran Kyai Haji Ahmad Dahlan, Muhammadiyah dalam Perspektif Perubahan Sosial (Cetakan 1). Jakarta: Bumi Aksara.

Ni'mah, Z. A. (2014). PEMIKIRAN PENDIDIKAN ISLAM PERSPEKTIF KH. AHMAD DAHLAN (1869-1923 M) DAN KH. HASYIM ASY'ARI 1871-1947) M): Study Komparatif dalam Konsep Pembaruan Pendidikan Islam di Indonesia. Didaktika Religia. https://doi.org/10.30762/didaktika.v2i1.136

Sugiyono. (2015). Metode Penelitian Pendidikan (Pendekatan Kuantitatif, Kualitatif, dan $R \& D)$. Bandung: Alfabeta.

Suwarno, S. (2019). KELAHIRAN MUHAMMADIYAH DARI PERSPEKTIF HERMENEUTIK. SASDAYA: Gadjah Mada Journal of Humanities. https://doi.org/10.22146/sasdayajournal.43886

Umar, B. (2010). IImu Pendidikan Islam (Cetakan 1). Jakarta: Amzah.

Wirjosukarto, A. H. (1962). Pembaharuan pen-didikan dan pengajaran Islam yang diselenggarakan oleh pergerakan Muhammadiyah. Yogyakarta: Penyelenggara publikasi pebaharuan pendidikan/pengajaran Islam.

Yunus, M. (1960). Sejarah Pendidikan Islam di Indonesia. Jakarta: Pustaka Mahmudah. 